\title{
POLÍTICAS PÚBLICAS PARA A LEITURA E MATERIALISMO HISTÓRICO DIALÉTICO: LEVANTAMENTO SOBRE AS PRODUÇÕES ACADÊMICAS (2013-2016)
}

\author{
POLÍTICAS PÚBLICAS PARA LA LECTURA Y MATERIALISMO HISTÓRICO \\ DIALÉTICO: LEVANTAMIENTO SOBRE LAS PRODUCCIONES ACADÉMICAS \\ (2013-2016)
}

\begin{abstract}
PUBLIC POLICIES FOR READING AND HISTORICAL DIALECTICAL MATERIALISM: SURVEY ON ACADEMIC PRODUCTIONS (2013-2016)
\end{abstract}

\author{
Katia Silva BUFALO ${ }^{1}$ \\ Maria José Ferreira RUIZ ${ }^{2}$
}

RESUMO: O texto apresenta resultado parcial de estudo realizado no Grupo de Pesquisa Estado, Política e gestão da educação, no Projeto: Contribuições do Materialismo Histórico para as Pesquisas em Políticas Educacionais. Reconhece o Materialismo Histórico como fundamento teórico metodológico que oferece elementos epistemológicos e ontológicos para o pesquisador compreender a totalidade de seu objeto de estudo na sociedade capitalista. $\mathrm{O}$ objetivo geral é identificar as contribuições do Materialismo Histórico Dialético para as pesquisas que discutem políticas de democratização do livro e da leitura entre os anos de 2013 e 2016. O estudo foi realizado por meio de pesquisa bibliográfica sobre o MHD e levantamento de teses e dissertações nas bibliotecas digitais. Conclui que apenas uma pequena parcela se apoia neste método e muitas destes estudos não anunciam de forma clara a perspectiva metodológica na qual embasam suas discussões.

PALAVRAS-CHAVE: Materialismo histórico dialético. Políticas públicas de leitura. Mercantilização da educação.

RESUMEN: El texto presenta un resultado parcial de estudio realizado en el Grupo de Investigación Estado, políticas públicas y gestión de la educación, en el Proyecto: Contribuciones del Materialismo Histórico para las Investigaciones en Políticas Educativas. Reconoce el Materialismo Histórico como fundamento teórico metodológico que ofrece elementos epistemológicos y ontológicos para el investigador comprender la totalidad de su objeto de estudio en la sociedad capitalista. El objetivo general es identificar las contribuciones del Materialismo Histórico Dialéctico para las investigaciones que discuten políticas de democratización del libro y de la lectura entre los años de 2013 y 2016 . El estudio fue realizado por medio de la investigación bibliográfica sobre el MHD y el levantamiento de tesis y disertaciones en las bibliotecas digitales. Concluye que sólo una pequeña parcela se apoya en este método y muchos de estos estudios no anuncian de forma clara la perspectiva metodológica en la que basan sus discusiones.

PALABRAS CLAVE: Materialismo histórico dialéctico. Políticas públicas de lectura. Mercantilización de la educación.

${ }^{1}$ Universidade Estadual de Londrina (UEL), Londrina - PR - Brasil. Professora Pedagoga SEED-PR. ORCID: <https://orcid.org/0000-0003-1706-2454>.E-mail: ksbufalo@hotmail.com

${ }^{2}$ Universidade Estadual de Londrina (UEL), Londrina - PR - Brasil. Docente do Departamento de Educação. ORCID: <https://orcid.org/0000-0002-1904-8878>. E-mail: mjfruiz@ gmail.com

RPGE- Revista on line de Política e Gestão Educacional, Araraquara, v. 22, n. 3, p. 978-991, set./dez. 2018. E-ISSN:1519-9029. DOI: 10.22633/rpge.v22i3.11322 
ABSTRACT: The text presents partial results of a study carried out in the State Research Group, policies and education management, in the Project: Contributions of Historical Materialism for Research in Educational Policies. It recognizes Historical Materialism as a theoretical and methodological foundation that offers epistemological and ontological elements for the researcher to understand the totality of his object of study in capitalist society. The general objective is to identify the contributions of the Dialectical Historical Materialism to the researches that discuss the democratization policies of the book and the reading between the years of 2013 and 2016. The study was carried out through bibliographic research on the MHD and the collection of theses and dissertations in digital libraries. It concludes that only a small portion relies on this method and many of these studies do not clearly announce the methodological perspective on which they base their discussions.

KEYWORDS: Dialectical historical materialism. Public reading policies. Mercantilization of education.

\section{Introdução}

O texto é fruto de discussões realizadas em Projeto de Pesquisa que visa verificar as contribuições do Materialismo Histórico Dialético para as pesquisas em Políticas Educacionais. Para tanto, cada pesquisador responsabiliza-se por fazer esta verificação, tendo em vista uma política específica, de acordo com o objeto de estudo de sua pesquisa particular, realizada neste Grupo. Neste texto, em específico, o objetivo geral é verificar as contribuições do Materialismo Histórico Dialético para as pesquisas que discutem políticas de democratização do livro e da leitura. Como objetivo específico, buscamos identificar nos estudos sobre as políticas de livro e leitura no Brasil, realizados entre os anos de 2013 e 2016, se utilizam ou não o MHD, como método do estudo.

Para isso, fizemos um levantamento de pesquisas realizado no Catálogo de Teses e Dissertações da Coordenação de Aperfeiçoamento de Pessoal de Nível Superior (CAPES), além de busca na rede mundial de computadores, por meio do website Google, no ano de 2016 com os principais descritores: Políticas de Leitura; PNLL (Plano Nacional do Livro e Leitura) e Democratização da Leitura, os trabalhos referenciados foram selecionados a partir da leitura dos resumos.

A fim de sistematizar didaticamente nossos achados, organizamos o texto a seguir em duas seções. Na primeira apresentamos o Materialismo Histórico Dialético como método de estudo, suas categorias de análise e contribuições para o entendimento das contradições, avanços e limites para a efetivação das políticas para o livro e leitura. A seguir expomos dados do balanço da produção acadêmica sobre políticas públicas para o livro e a leitura, no quadriênio 2013-2016. 
Políticas públicas para a leitura e materialismo histórico dialético: levantamento sobre as produções acadêmicas (2013-2016)

\section{O materialismo histórico: uma perspectiva teórica que se fundamenta na realidade}

De acordo com Tonet (2013), a ciência moderna colocou o método científico como instrumento inquestionável de produzir o conhecimento. Nesta perspectiva, o importante na busca pelo conhecimento é o rigor metodológico, compreendendo a precisão na execução das etapas estabelecidas pelo método, o cuidado quanto à inserção de elementos não reconhecidos pelo conhecimento e intersubjetividade, isto porque,

[...] o método científico moderno, pois é unicamente a forma e não o conteúdo que garante - na medida em que pode garantir - o sucesso do conhecimento. Por sua vez, a intersubjetividade, ou seja, o debate entre os cientistas é a maneira de tentar escapar do relativismo, consequência que brota da não existência de parâmetros objetivos para a validação do conhecimento. (TONET, 2013, p. 47).

Netto (2011), em relação a teoria social de Marx, entende que a questão do método se revela como um desafio, em razão de que "o estudo da concepção teórico-metodológica de Marx apresenta inúmeras dificuldades - desde as derivadas da sua própria complexidade até as que se devem aos tratamentos equivocados a que a obra marxiana foi submetida". (NETTO, 2011, p. 11). Assim, no plano teórico-metodológico, utilizamos a abordagem materialista histórica, no intuito de compreender as políticas públicas, com a compreensão que,

Os pressupostos de que partimos não são pressupostos arbitrários, dogmas, mas pressupostos reais, de que só se pode abstrair na imaginação. São os indivíduos reais, sua ação e suas condições materiais de vida, tanto aquelas por eles já encontradas como produzidas por sua própria ação. Esses pressupostos são, portanto, constatáveis por via puramente empírica. (MARX; ENGELS, 2016, p. 86-87).

Em outras palavras "[...] na vida real, começa também, portanto, a ciência real, positiva, a exposição da atividade prática, do processo prático de desenvolvimento dos homens”. (MARX; ENGELS, 2016, p. 95). Compreendemos, a partir dessa perspectiva metodológica, que as políticas públicas não são propostas de forma abstrata, mas sim, fruto das relações estabelecidas em uma sociedade dividida em classes, mediadas pelo Estado. Sendo assim, entendemos a realidade "[..] sob a forma contraditória de relações entre classes, expressas não só na exploração do trabalho pelo capital, mas também na tentativa de direção axiológica, forma sob a qual os discursos pedagógicos dominantes tentam ocultar a luta de classes". (CURY, 1989, p. 16). Neste sentido, no que se refere especificamente à política pública para a educação, Masson (2013) afirma que [...] "é imprescindível, nas investigações 
sobre políticas educativas, além de compreender o sistema do capital, apreender o papel do Estado moderno e suas transformações históricas" (MASSON, 2013, p. 66 - grifo da autora).

Tendo isso em vista, entendemos que as categorias do MHD configuram os elementos gerais e essenciais dos fenômenos estudados. A seguir, apresentamos uma síntese das categorias conceituais do MHD apresentadas por Cury (1989), quais sejam: hegemonia, reprodução, mediação, totalidade e contradição, fazendo o esforço de relacionar estas cinco categorias às questões que medeiam as políticas de livro e leitura.

Para este autor a hegemonia caracteriza-se pela formação de um conjunto de necessidades que irão gerar diretrizes e princípios dirigidos pelo Estado. "Logo, o conteúdo cultural da hegemonia não se dá por ela mesma, mas sim na relação entre dirigentes e dirigidos, portanto numa relação historicizada”. (CURY, 1989, p. 49 - grifo nosso). Nesse sentido, a hegemonia pode ser identificada como o conjunto de ideias que apontam a direção em que a sociedade deve se desenvolver, num contexto histórico de avanço do sistema capitalista, sendo que o efeito das ideias hegemônicas propicia momentos de consenso nas relações de dominação.

Assim, todas as relações sociais refletem-se em relações políticas movidas pela contradição das relações de dominação que, em síntese, pretendem manter a reprodução das relações de produção. Essa lógica, que se constitui em política de dominação, necessita da presença do Estado, como instrumento regulador e organizador do modo de produção capitalista. De acordo com Cury (1989):

O jogo dessa função contraditória preside à administração, à alocação, dos bens e serviços públicos e à função técnica e política da educação, por exemplo quando o Estado define as prioridades ao investir em projetos e serviços que garantam a acumulação pelo aumento da produtividade e pela redução do custo da reprodução da forma de trabalho. (CURY, 1989, p. 55 - grifo nosso).

Sobre a dimensão hegemônica da educação, é importante lembrar que o Estado, ao mesmo tempo em que estende o direito à educação para todos pelo discurso da universalização, num duplo movimento, instala programas de distribuição de livros atendendo às prioridades do modo de produção e, em muitas vezes, esses livros não têm espaço físico para serem organizados para utilização nas escolas. Contudo, é indiscutível que livros são materiais importantes para o processo educativo e soa como retrógrados aqueles que se opuserem ao envio de livros para as instituições escolares. Simultaneamente, o Estado também instala programas de avaliações em larga escala, como indicador de análise da 
qualidade do ensino, relacionando a educação como uma forma de conquista pessoal, individual e meritocrática, projetando sobre os sujeitos (alunos e professores), a responsabilidade sobre o possível sucesso ou fracasso, questionando a competência e pertinência da educação como política pública, omitindo a redução de custos no processo e propagando um modo de pensar que reorienta as relações de classe em consequência da ação hegemônica.

Conforme Cury (1989), a análise da categoria da hegemonia "exige a análise das formas ideológicas através das quais a classe dominante busca um conformismo, ou seja, busca transformar sua concepção de mundo em senso comum". (CURY, 1989, p. 29 - grifo do autor). Nesse contexto, consolida-se a lógica da hegemonia, na medida em que, de fato, o Estado, atuando como regulador das relações sociais na sociedade capitalista elabora políticas que atendem, em parte, as demandas das classes dominadas, ou seja, distribui livros para alunos e professores na escola pública; no entanto, o tempo escolar para trabalhar a leitura, o espaço físico e até a mesmo a formação dos professores em relação a essas políticas não são efetivamente consolidadas.

De fato, o mercado editorial tem-se fortalecido crescentemente pela venda de livros para os programas de livro leitura, em que se observa uma relação de produção e consumo justificada como política pública, de forma a que, a manutenção dos meios de produção do livro é colocada como interesse coletivo em prol da democratização do acesso como ideia hegemônica sobre formar leitores.

As relações hegemônicas estão imbricadas entre as relações da educação e reprodução. Sobre esta segunda categoria, a reprodução, Cury (1989) enfatiza que ela expressa a totalidade histórica do modo de produção capitalista. Portanto, a educação desempenha funções diretamente associadas às relações de produção. Para Cury (1989), a educação participa das relações de produção como instância, não exclusiva, de formação da força de trabalho e reprodutora dos ideais dominantes, resultado de práticas escolares análogas à divisão do trabalho. Nesta perspectiva, é crucial alertar sobre a "fragmentação da leitura na escola", envolvida pela separação entre teoria e prática, dicotomia identificada por Cury (1989), na dimensão da reprodução: função técnica e função política. A fragmentação da leitura se dá na concepção e defesa de aulas de leitura, além de projetos de leitura. Contudo, a leitura em si, o ato de ler, não está consolidado no interior dos programas como práxis, visto que, tanto os estudos que apoiam-se em abordagens quantitativas quanto análises qualitativas e críticas apontam que o nível de proficiência dos estudantes brasileiros na maioria das avaliações revela-se insuficiente. 
De fato, as proposições acerca da leitura são balizadas no atual modo de produção. Conforme Cury (1989), a fase atual do capitalismo não nega às crianças e jovens da classe trabalhadora o direito à educação. Contudo, o movimento do capitalismo exige que a educação se efetive como mantenedora da estrutura econômica e social como reprodutora da organização e divisão social do trabalho. "O sistema escolar estrutura-se de forma fragmentada reproduzindo a divisão social do trabalho e a lógica do mercado. O acesso ao conhecimento dá-se de maneira profundamente desigual e seletiva”. (SAVIANI; DUARTE, 2012, p. 2).

A terceira categoria do MHD, apontada por Cury (1989), trata-se da mediação que revela-se no espaço em que as teorias se concretizam e indicam a direção do projeto político educativo e as ações para sua concretização. De acordo com Cury (1989) "Marx teria sugerido que a reprodução da relação capitalista também é uma mediação. $\mathrm{O}$ que abre caminho para outras formas de mediações entre as quais se pode situar a educação". (CURY, 1989, p. 64). Ainda segundo este autor, a categoria mediação na educação pode ser compreendida como elemento articulador das relações antagônicas da sociedade de classes.

Sobre as proposições relacionadas à mediação da leitura na educação pública, a partir da prática profissional vivenciada, observamos uma tendência que tem feito parte da cultura escolar, o predomínio nas escolas de tentativas de organização de horários semanais para os alunos realizarem empréstimos de livros, apenas, sem ter uma integração com os estudos das aulas e do projeto político pedagógico da escola. Outra prática recorrente em relação às mediações de leitura tem sido a organização de visitas às contações de histórias em bibliotecas e/ou às feiras de livros.

Essas atividades de "passeios", ou visitas às feiras culturais ocorrem periodicamente em parceria com organizadores que, via de regra, são instituições vinculadas às editoras e/ou ao setor privado. As escolas estatais levam os alunos para frequentarem essas feiras de livros e contações de histórias, mediando e reproduzindo a ideia de que para ler basta comprar livros. Identificamos nesses procedimentos da cultura escolar a mediação mercantilizada da leitura, conforme, Silva (2014),

A leitura no processo da mercantilização é posta como produto da escola e critério para ingresso e participação do indivíduo na sociedade. Veio a ser valorizada como ideia, por distinguir o homem alfabetizado e culto do analfabeto e ignorante, acentuando, assim, a clivagem social e colocando o ato de ler como um ideal a perseguir. $O$ ainda não leitor se apresenta na situação primitiva de falta, que lhe cumpre superar, se deseja ascender ao mundo civilizado da propriedade, por consequência, do dinheiro e da fortuna. (SILVA, A.M.O.C., 2014, p. 46 - grifo nosso). 
Não há dúvidas de que visitar feiras e ouvir narrativas de histórias contribuem para o interesse pela leitura, entretanto, há nessa prática um determinante econômico, relacionado à propriedade, ter o livro; dessa forma, as desigualdades sociais e econômicas às quais é submetida a ampla maioria dos alunos de escolas públicas, faz dessa experiência algo distante, contraditório e alicerce de conflitos. Contudo, na escola há livros oriundos do Programa Nacional Biblioteca da Escola - PNBE, sendo assim, a prioridade da escola para possibilitar o ato de ler deve ser no sentido de mediar práticas pedagógicas que priorizem a utilização do acervo e do ambiente da biblioteca escolar. O passeio às feiras é contrário ao sentido de universalização do conhecimento que a escola deve realizar. Posto isto, a escola pode optar entre dois caminhos, conforme Cury (1989), "a educação como mediação entre uma forma de ação que corrobora a permanência e/ou uma forma de ação que conduza à transformação social”. (CURY, 1989, p. 66).

A quarta categoria do MHD apontada por este autor é a totalidade que é aberta e concreta e só pode ser compreendida em relação a si e aos outros fenômenos, uma vez que a educação em sua totalidade implica considerar as contradições. "A natureza dessas contradições, seus ritmos, as condições de seus limites, controles e soluções dependem da estrutura de cada totalidade - e, [...] não há fórmulas apriorísticas para determiná-las: também cabe à pesquisa descobri-las". (NETTO, 2011, p. 57).

Como se trata de uma totalidade dentro de totalidades, as políticas públicas para leitura também podem ser observadas nesse horizonte, isto é, o fato de as políticas públicas favorecerem em primeira ordem a manutenção das relações de produção do mercado editorial abre espaços e possibilidades reais de acesso à leitura, ou melhor, às fontes do conhecimento. Sobre a contradição, Cury (1989) ainda esclarece que o conhecimento sobre o que é geral no movimento possibilita identificar o que é essencial no processo e o conhecimento sobre o que é específico no fenômeno contraditório amplia a compreensão do objeto, fundamentados na realidade, uma vez que o entendimento concreto dar-se-á na dimensão de cada totalidade histórica. Segundo o autor, a contradição constitui o motor interno da história. Assim sendo, "Na sociedade capitalista, o movimento se dá em consequência do desenvolvimento das contradições que existem em seu seio. Tais contradições se revelam no papel motor da luta de classes na transformação social”. (CURY, 1989, p. 33).

Denunciar as contradições e buscar uma leitura crítica sobre a estrutura de um fenômeno é assumir uma postura política e uma visão de mundo. Entendemos que não pode ser natural do Estado brasileiro estabelecer um Plano Nacional do Livro e Leitura, desde 2006, e depois de uma década de sua aprovação, continuar a divulgar índices vexatórios de 
leitura. Identificamos nessa ocorrência contraditória uma necessidade de pesquisa e um espaço de luta em defesa pela educação pública/estatal e pela socialização do conhecimento em suas formas mais desenvolvidas.

Conforme a reflexão de Cury (1989), “A possibilidade de que a educação assuma a função política de arma crítica existe porque a reprodução das relações sociais de produção não é mera repetição das mesmas". (CURY, 1989, p. 83-84). Nesse sentido, compartilhamos também do entendimento de Frigotto (2010), "Esse movimento é um movimento prático, empírico. Há, pois, a exigência necessária de uma concepção da realidade, um método capaz de desvendar as 'leis' fundamentais que estruturam um problema que se investiga". (FRIGOTTO, 2010, p. 95). Contudo, o autor esclarece,

É importante ressaltar que quem conduz a investigação é o investigador e não os dados, sejam primários ou secundários. É o pesquisador que estrutura as questões e sua significação para conduzir a análise dos fatos, dos documentos etc. Com isso está se afirmando que o investigador vai à realidade com uma postura teórica desde o início. A questão crucial é estabelecer um inventário crítico desta postura em face do objeto que se está investigando e não abstratamente. (FRIGOTTO, 2010, p. 97- grifo nosso).

Desse modo, delimitamos nossa concepção quanto à fundamentação da metodologia de pesquisa a partir do Materialismo Histórico Dialético. "Não só o recorte ou a problemática específica a ser investigada necessita ser apreendida com a totalidade de que faz parte, como é importante ter presente a que sujeitos históricos reais a pesquisa se refere". (FRIGOTTO, 2010, p. 96). Nesta concepção, o conhecimento da realidade social significa apropriar-se da totalidade concreta e compreender:

[...] um processo indivisível, cujos momentos são: a destruição da pseudoconcreticidade, isto é, da fetichista e aparente objetividade do fenômeno, e o conhecimento do caráter histórico do fenômeno, no qual se manifesta de modo característico a dialética do individual e do humano em geral; e enfim o conhecimento do conteúdo objetivo e do significado do fenômeno, da função objetiva e do lugar histórico que ela ocupa no seio do corpo social. Se o conhecimento não determinou a destruição da pseudoconcreticidade, se não descobriu, por baixo, da aparente objetividade do fenômeno, sua autêntica objetividade histórica, assim confundindo a pseudoconcreticidade com a concreticidade, ele se torna prisioneiro da intuição fetichista, cujo produto é a má totalidade. (KOSIK, 1995, p. 61).

Nesta perspectiva, foi possível constatar a carência de contribuições sobre a relação das políticas públicas de leitura para escola pública/estatal e o papel do Estado nessa totalidade. Destacamos os determinantes históricos, por meio do método do Materialismo Histórico Dialético, a fim de elaborar sínteses propositivas para contribuir com a 
transformação da realidade social. Portanto, considerando o número de produções encontradas nessa abordagem teórica metodológica ressaltamos a necessidade de ampliação das pesquisas que contribuam para esse intuito.

A partir das premissas supracitadas, sobre os pressupostos metodológicos nos quais nos pautamos, apresentamos a seguir um levantamento sobre as produções acadêmicas encontradas no período de 2013-2016 relacionadas às políticas públicas de leitura, em vista disso, busca-se identificar nestas produções quais utilizam o Materialismo Histórico Dialético como fundamentação metodológica, a fim de estabelecer uma aproximação e aprofundamento dos resultados encontrados nesse e em outros estudos.

\section{Balanço da produção acadêmica no quadriênio 2013-2016}

O tema da leitura é contemplado em muitas pesquisas e diversas instituições, entretanto, quando classificamos essas produções por regiões do país podemos observar as desigualdades vivenciadas, pois há uma diferença considerável entre o número de trabalhos realizados na região sudeste em relação às demais regiões do país, fato comprovado por meio da história da educação no Brasil que registra a criação de escolas e universidades nas regiões vinculadas ao processo de industrialização. Contudo, quando associamos o termo Políticas Públicas de Leitura há uma redução considerável de trabalhos e se, acrescermos a essa busca o termo Materialismo Histórico Dialético o resultado quantitativo fica ainda mais restrito. Com base na leitura dos resumos foram selecionados vinte e quatro trabalhos disponibilizados no Catálogo de Teses e Dissertações - CAPES, no período estipulado, conforme quadro a seguir.

Quadro 1 - Dissertações e teses sobre políticas públicas para leitura

\begin{tabular}{|c|c|c|c|c|}
\hline Ano & $\begin{array}{l}\text { Total de } \\
\text { Dissertações }\end{array}$ & $\begin{array}{c}\text { Dissertações que } \\
\text { anunciam o } \text { MHD }^{3} \\
\text { como método }\end{array}$ & $\begin{array}{l}\text { Total de } \\
\text { Teses }\end{array}$ & $\begin{array}{l}\text { Teses que anunciam o } \\
\text { MHD como método }\end{array}$ \\
\hline 2013 & 1 & 0 & 4 & 1 \\
\hline 2014 & 8 & 2 & 1 & 0 \\
\hline 2015 & 6 & 0 & 1 & 0 \\
\hline 2016 & 3 & 0 & 0 & 0 \\
\hline TOTAL & 18 & 2 & 6 & 1 \\
\hline
\end{tabular}

Fonte: Catálogo de Teses e Dissertações (2016). Elaborado pelas autoras

${ }^{3}$ MHD: Materialismo Histórico Dialético. 
Dentre as vinte e quatro pesquisas selecionadas constatou-se que apenas três trabalhos utilizam o Materialismo Histórico Dialético como fundamentação teórico-metodológica, ou seja, pouco mais de dez por cento, aliás, um índice bem baixo. Contudo, destacamos que há autores que não são precisos em relação ao método da pesquisa na escrita do resumo o que dificulta o levantamento. Porém, é possível identificar nas teses e dissertações descritas, por meio dos resumos estudados um predomínio da abordagem da história cultural. Identifica-se ainda outras abordagens tais como a semiótica (teoria do discurso), psicologia sócio histórica e pós-estruturalismo.

Deste modo, organizamos os trabalhos por aproximação das discussões e identificamos três grupos de temáticas conforme o quadro abaixo:

Quadro 2 - Eixos temáticos das teses e dissertações sobre políticas públicas para leitura

\begin{tabular}{|c|c|c|}
\hline \multicolumn{1}{|c|}{ Tema } & $\begin{array}{l}\text { Número de } \\
\text { pesquisas }\end{array}$ & $\%$ \\
\hline Políticas públicas para o livro e a leitura & 13 & 29,1 \\
\hline Programas do livro e leitura para a escola estatal & 7 & 16,6 \\
\hline Mercantilização da educação & 4 & 54,6 \\
\hline
\end{tabular}

Fonte: Elaborado pelas autoras a partir do levantamento realizado no Catálogo de Teses e Dissertações (2016)

O quadro exposto representa a discussão essencial do fenômeno das pesquisas sobre a leitura a partir da abordagem teórico-metodológica utilizada. Ao observarmos a aproximação dos trabalhos verificamos que a maior parte discute as políticas públicas de livro e leitura, enfocando muito mais a mercadoria livro, em vez de buscar compreender os determinantes históricos, políticos e sociais que impedem a prática social da leitura. No grupo de trabalhos organizados com a temática dos programas de livro e leitura para a escola estatal verificou-se um predomínio de discussões em torno de objetos delimitados pelo conteúdo dos livros e o trabalho docente, e em sua maioria, de forma seccionada. O menor grupo dos trabalhos discute a relação das políticas públicas de leitura com o mercado e a mercantilização da educação, correspondente ao número de quatro trabalhos, três deles utilizam o Materialismo Histórico Dialético, como fundamentação teórico-metodológica.

Nesse contexto, recorremos a Silva (2013) para expressar o que envolve optar por essa ou aquelas perspectivas teóricas. "Entende-se que o Estado, ao promover a distribuição 
gratuita de milhões de livros didáticos (entre outros materiais escolares) por meio do Programa Nacional do Livro Didático, movimenta o mercado na sua totalidade". (SILVA, 2013, p. 249). Isto por que, pesquisar política pública de livro e leitura no Brasil perpassa obrigatoriamente a discussão do Programa do Livro Didático, considerando que, de todos os programas mediados pelo Estado, este se manteve historicamente desde os anos 1930 e foi continuamente ampliado. "Esta política de aquisição de livros didáticos pelo governo brasileiro transformou-se num grande negócio que contribuiu para o processo de oligopolização e entrada do capital estrangeiro no setor editorial”. (SILVA, 2012, p. 817).

Entendemos que os trabalhos que discutem a realidade a partir do Materialismo Histórico Dialético elucidam a contradição estabelecida entre o número cada vez maior de programas e recursos destinados para o livro e o nível insuficiente de proficiência de leitura dos estudantes brasileiros. Na concepção de um destes trabalhos, observa-se que o que,

[...] está em curso [é] um processo de mercantilização da educação de novo gênero. A diferença específica do atual cenário do mercado editorial e, provavelmente, da mercadoria educacional como um todo, é a hegemonia financeira, em contraste com os negócios educacionais sob controle de capitalistas funcionantes. (PINHEIRO, 2014, p. 102).

Sendo assim, indagar sobre a realidade das políticas públicas para o livro e a leitura exige primeiramente entender a totalidade em que essas políticas estão inseridas, compreender o que há de geral na conjuntura atual para podermos identificar o que as políticas para o livro e a leitura apresentam de singular na realidade brasileira. De acordo com Peroni (2016), a essência do movimento do Estado na mediação das atuais políticas públicas e, em nosso caso, estendido às políticas para o livro e a leitura, consiste na "relação entre o público e o privado na direção e execução da educação é um processo de correlação de forças, que não ocorre por acaso e que está cada vez mais dando a direção da política pública”. (PERONI, 2016, p. 17).

Identificamos esse movimento em relação às políticas públicas para o livro e leitura, em nossa atualidade, com a progressiva abertura do PNLD para os sistemas privados de ensino, assim como na atual Reforma da Base Nacional Comum Curricular (BNCC) e os novos rumos implícitos nesse processo para a educação pública, como também a recente modificação do PNLD para o Programa Nacional de Livro e do Material Didático - PNLMD, segundo o Decreto No 9.099 de 18 de julho de 2017.

Em análise aos estudos selecionados, podemos afirmar que as políticas para a democratização da leitura, enquanto objeto de estudo, têm uma produção acadêmica consistente, tanto no âmbito nacional como mundial, haja vista que, ler é condição essencial 
para viver no estágio atual do capitalismo, nossa sociedade tornou-se grafocêntrica e assim, a prática social da leitura permeia a sociabilidade no modo de produção e consequentemente é condição necessária para todo ser humano. Contudo, embora a leitura tenha essa importância histórica, pois, é uma ação que está diretamente relacionada com o desenvolvimento da humanidade, a maioria das pesquisas realizadas, ainda que, apresentem contribuições importantes envolvendo variados aspectos acerca do fenômeno da leitura, carecem de mais clareza quanto a explicitação das fundamentações teórica-metodológica que as embasam. Entendemos que isso é de fundamental importância para dar pistas aos futuros leitores e interlocutores sobre a concepção que têm a respeito de como compreendem a sociedade, o Estado e outros elementos, sem os quais os dados destes estudos podem cair em uma concepção abstrata que se afasta da realidade objetiva.

\section{Considerações finais}

Após o levantamento sobre a produção acadêmica disponível acerca das políticas públicas de leitura foi possível constatar que a maioria dos trabalhos utiliza fundamentação teórica metodológica diferente do Materialismo Histórico Dialético. Em nosso entendimento a pesquisa realizada a partir deste método pressupõe elementos epistemológicos e ontológicos que possibilita compreender a sociedade em sua totalidade.

Contudo, identificamos trabalhos que apresentam importantes contribuições sobre a realidade social das políticas públicas para o livro e a leitura e indicam a necessidade de combater o eminente processo de mercantilização da educação que nesse objeto de estudo se materializa pela prática hegemônica de fetichização da mercadoria livro.

Por essa razão, apresentamos uma leitura do objeto em questão, políticas públicas para a leitura numa relação historicizada a partir das categorias da hegemonia, mediação, reprodução, contradição e totalidade, no intuito, de revelar a totalidade concreta, pois assim como os documentos oficiais sobre as políticas para o livro e a leitura, concordamos e defendemos a democratização da leitura.

A democratização da leitura, em nossa perspectiva, precisa ir além da questão mercadológica. Precisa ter em vista a formação plena do sujeito político, que conduza à emancipação humana, por meio do conhecimento que se adquire mediante a formação da atividade leitora.

Portanto, democratizar a leitura significa garantir condições de aprendizagem da leitura como prática social de todos os estudantes; nesse sentido, não existe nada mais 
Políticas públicas para a leitura e materialismo histórico dialético: levantamento sobre as produções acadêmicas (2013-2016)

revolucionário para o sistema educacional brasileiro do que democratizar a leitura. Por esse motivo, emerge a necessidade de problematizar sobre o tipo de democratização a que se referem os documentos de políticas públicas para o livro e a leitura no Brasil.

Defendemos a atividade leitora na escola. Para tanto, é preciso requerer as condições materiais e humanas para acontecer à prática social da leitura, principalmente, num momento em que as condições de trabalho estão cada vez mais acirradas; as propostas de vários governos sobre as negociações do trabalho docente recorrem em propor a diminuição da hora/atividade, entre outras medidas, caracterizando o professor como um "trabalhador horista", quase um empreiteiro. Consideramos que essas proposições são absolutamente contrárias a uma política de formação de leitores e suspeitamos que sejam conscientes e intencionais como estratégia de combate na luta de classes. Portanto, destacamos a necessidade de contemplar em pesquisas e ações políticas a formação docente e a discussão das condições de trabalho como proposições efetivas em torno da política pública para a leitura e formação de leitores.

\section{REFERÊNCIAS}

CURY, C.R. J. Educação e contradição: elementos teóricos metodológicos para uma teoria crítica do fenômeno educativo. São Paulo: Cortez, 1989.

FRIGOTTO, G. O enfoque da dialética materialista histórica na pesquisa educacional. IN: FAZENDA, I. (Org.). Metodologia da pesquisa educacional. São Paulo: Cortez, 2010.

KOSIK, K. Dialética do concreto. Rio de Janeiro: Paz e Terra, 1995.

MARX, K.; ENGELS, F. A ideologia alemã: crítica da mais recente filosofia em seus representantes Feuerbach, B.Bauer e Stirner, e do socialismo alemão em seus diferentes profetas (1845-1846). São Paulo: Boitempo, 2016.

MASSON, G. Orientações para o desenvolvimento de investigação em políticas educativas a partir da teoria marxista. In: TELLO, C.; ALMEIDA, M.L.P. Estudos epistemológicos no campo da pesquisa em política educacional. Campinas: Mercado de Letras, 2013.

NETTO, J. P. Introdução ao estudo do método de Marx. São Paulo: Expressão Popular, 2011.

PERONI, V. Implicações da relação público-privada para a democratização da educação. In: Reunião Científica Regional da ANPED, 2016, Curitiba. Anais... Curitiba: 2016, p. 1-21.

PINHEIRO, D. C. F. A educação sob controle do capital financeiro: O caso do Programa Nacional do Livro Didático. Dissertação. (Mestrado em Educação). Faculdade de Educação. Universidade Federal do Rio de Janeiro. RJ, 2014. 
SAVIANI, D; DUARTE, N. (Orgs). Pedagogia histórico-crítica e luta de classes na educação escolar. Campinas: Autores Associados, 2012.

SILVA, A. M. O. C. O discurso da democratização do acesso à leitura nas políticas públicas do Estado brasileiro: condições de produção e efeitos de sentido da mercantilização. Dissertação. (Mestrado em Educação). Centro de Educação. Universidade Federal de Alagoas, Maceió, 2014.

SILVA, I. A. O Programa Nacional do Livro Didático para o Ensino Médio (PNLD/EM) e o mercado editorial: 2003-2011. Tese (Doutorado em Educação). Centro de Ciências Humanas e Sociais. Universidade Federal do Mato Grosso do Sul, Campo Grande, 2013.

SILVA, M. A. A Fetichização do Livro Didático no Brasil. Educação Real, Porto Alegre, v. 37, n. 3, p, 803-821, set - dez 2012.

TONET, I. Método Científico: uma abordagem ontológica. São Paulo, Instituto Lukács, 2013.

\section{Como referenciar este artigo}

BUFALO, Katia Silva; RUIZ, Maria José Ferreira. Políticas públicas para a leitura e Materialismo Histórico Dialético: levantamento sobre as produções acadêmicas (2013-2016). Revista on line de Política e Gestão Educacional, Araraquara, v. 22, n. 3, p. 978-991, set./dez. 2018. E-ISSN:1519-9029. DOI: 10.22633/rpge.v22i3.11322

Submetido em: $27 / 04 / 2018$

Aprovado em: 30/06/2018 